

\section{Cacería de puercoespines: políticas públicas para países de renta media}

Mariana Cerrilla'

Resumen La economía creativa es considerada como estratégica para el desarrollo de los países. Su impacto va más allá de un aspecto cultural, contribuyendo de manera importante al valor agregado, empleo y comercio exterior de las economías. A pesar de lo anterior, muchos países en desarrollo no han implementado políticas públicas que lleven al desarrollo de las industrias culturales y creativas. El presente estudio busca analizar la regulación aplicable a la economía creativa en diez países de renta media, con el fin de determinar si ésta influye en la contribución económica que tienen estas industrias en el Producto Interno Bruto y empleo de un país.

Palabras clave economía creativa, cultura, derecho de autor, regulación.

Abstract The creative economy is increasingly considered as strategic for the development of countries. Its impact goes beyond a cultural aspect, contributing significantly to the value added, employment and foreign trade in an economy, although, many developing countries have not implemented policies that lead to the development of cultural and creative industries. The present study aims to analyze the regulation applicable to the Creative Economy in ten middle-income countries, in order to determine if this influences the economic contribution that these industries have in the GDP and employment in a country.

Keywords creative economy, culture, copyright, regulation. 
En los últimos años se ha desarrollado una creciente literatura sobre la importancia de la economía creativa en el desarrollo de un país, reconociendo a este sector como líder en la generación económica y uno de los más dinámicos en el mundo. En gran parte de los países desarrollados, las industrias creativas son consideradas como estratégicas en tanto han mostrado un dinamismo y crecimiento mayor al del resto de los sectores económicos.

El presente estudio busca, mediante el análisis de la regulación de la economía creativa, en específico de los derechos de autor y propiedad intelectual en diez países de renta media, determinar si las políticas aplicadas han impactado en la contribución de las industrias culturales y creativas a la economía de un país, ya sea como generadoras de empleo o de otros valores agregados que contribuyan al Producto Interno Bruto (PIB).

Se busca explicar a grandes rasgos qué es la economía creativa y cómo contribuye al desarrollo de un país, tanto desde un punto de vista económico, como cultural, social y de sostenibilidad. En este apartado se esbozan también las características económicas de las industrias creativas y culturales. Posteriormente, se presenta la evidencia empírica de la contribución de la economía creativa en 10 países de renta media y se analizan los diferentes sectores para mostrar las características específicas de las industrias en cada uno de los países seleccionados.

Con el fin de analizar la regulación existente en la materia antes enunciada, en la siguiente sección se presenta la legislación, tanto a nivel internacional como nacional, en materia de derechos de autor. En primer lugar, se analizan los diferentes tratados y convenios internacionales que enmarcan la legislación de los países analizados y que regulan los bienes protegidos por derechos de autor. A continuación se presentan las principales diferencias que existen, a grandes rasgos, en dicha legislación.

En la tercera sección se analizan diferentes índices diseñados por organismos internacionales, como el Banco Mundial, sobre competitividad, innovación y legalidad, a fin de explicar de manera más concreta los factores que podrían explicar las diferencias en la contribución económica, como porcentaje del valor agregado y del empleo que generan las industrias culturales y creativas en cada uno de los países seleccionados.

Finalmente, se presentan las conclusiones, así como las recomendaciones de políticas públicas que se deriven a partir del análisis.

\section{La economía creativa: Industrias culturales e industrias creativas}

Resulta complicado aportar una definición contundente y definitiva sobre la economía creativa, ya que existen múltiples interpretaciones según los intereses del organismo o la institución que las estudie. La Conferencia de las Naciones Unidas sobre Comercio y Desarrollo (UNCTAD, por sus siglas en inglés) define a las industrias creativas como aquellas que combinan la creación, producción y distribución de bienes y servicios que utilizan la creatividad y el capital intelectual como insumos primarios. Constituyen un conjunto de actividades basadas en el conocimiento, centrado en, pero no limitado a las artes, que potencialmente gene- 
ran ingresos del comercio y derechos de propiedad intelectual. Comprenden bienes tangibles y servicios intangibles intelectuales y artísticos con contenido creativo, valor económico y objetivos de mercado e incluyen las actividades artesanales, servicios y sectores industriales (UN, 2010).

El primero en utilizar el término fue el británico John Howkins. Dicho autor incluyó cuatro sectores: las industrias protegidas por derecho de autor, patentes, marcas e industrias del diseño, por lo que su definición abarcaba desde las artes, bienes y servicios culturales, tecnología y ciencia, investigación y desarrollo (R\&D), hasta juguetes y videojuegos (Howkins, 2001).

A partir de este año surgieron diferentes modelos que permiten clasificar las industrias culturales y creativas, siendo los más utilizados el DCMS, el modelo de textos simbólicos, el modelo de círculos concéntricos y el de la Organización Mundial de la Propiedad Intelectual (OMPI o WIPO, por sus siglas en inglés). La diferencia entre estos modelos ha sido estudiada ampliamente por la UNESCO (2013), por lo que aquí basta con mencionar que, si bien existen artes que comparten todos los modelos como la publicidad, televisión, radio, cine y video; el debate se centra en actividades como museos, juegos de computadora y deporte; así como en la clasificación que realiza cada uno sobre el tipo de industria.

Para el presente estudio se utiliza el modelo de la OMPI por dos razones. En primer lugar, al ser un estudio de política comparada resulta imprescindible que los resultados sean equiparables entre países. Al respecto, la OMPI es el organismo que ha desarrollado una metodología para medir la contribución económica y cuenta con resultados para un mayor número de países $y$, por lo tanto, es el más utilizado como referencia en los estudios internacionales. En segundo lugar, al abor- darse el tema de la regulación, la mayoría de las industrias creativas son reguladas por la propiedad intelectual, abarcando de esta forma la mayoría de la legislación en la materia. Si bien es cierto que existen otros ámbitos de legislación, como por ejemplo el de telecomunicaciones, sería necesario un estudio mucho más extenso que permita cubrir estos aspectos.

La OMPI define a las industrias protegidas por el derecho de autor como "aquellas que se dedican, son interdependientes, o que se relacionan directa e indirectamente con la creación, producción, representación, exhibición, comunicación, distribución o venta de material protegido por el derecho de autor" (OMPI, 2014). Si bien es cierto que este modelo impone ciertas restricciones al estudio, también permite obtener resultados más concluyentes y comparables. Entre las principales desventajas, podemos mencionar que no incluye algunas actividades culturales como el patrimonio, además de que, al incluir un amplio número de actividades relacionadas con las industrias protegidas por el derecho de autor como venta al por mayor, al por menor, fabricación, alquiler, entre otros, es decir, las industrias interdependientes o parciales, resulta complicado medir el efecto real de la parte creativa.

\section{Características de la economía} creativa

El impacto de las industrias creativas y culturales va más allá de un sector y cuenta con múltiples dimensiones. Desde el punto de vista económi$\mathrm{co}$, contribuyen igual que en otros sectores, a la generación de valor agregado y comercio exterior, pero su impacto se materializa también en un desarrollo más integral, equilibrado e incluyente, que genera bienestar. Según la UNCTAD, 
a pesar de que el comercio exterior se redujo $12 \%$ en 2008, el comercio mundial de bienes y servicios creativos creció a una tasa anual promedio de $14 \%$ de 2002 al 2008 (UNCTAD, 2010). Este aumento se debe a diversas razones, pero una de ellas, es el incremento en la demanda de estos productos, derivado del incremento en el ingreso en los países desarrollados.

Además, uno de los mayores motores de las industrias creativas es la tecnología. El avance tecnológico, la digitalización de los contenidos, Internet y los medios de comunicación han llevado a una disminución en los precios de los bienes creativos y culturales, pues han modificado la forma en que el contenido cultural y creativo es producido; incluso han desarrollado nuevas formas de expresión y narrativas. Pero principalmente, han modificado la forma en que el contenido es distribuido, puesto a disposición del público y los hábitos de consumo de este último. Esto presenta un reto pero también una oportunidad para los bienes culturales; ha permitido una multiplicación de los medios de explotación y ventanas de comercialización de dichos bienes, redefiniendo el mercado. También ha generado mayor diversidad cultural, ya que les ha dado la oportunidad a nuevos creadores, pero esto a su vez se ha traducido en un incremento de la competencia.

Por otra parte, la economía creativa contribuye, además, al empleo calificado ya que es intensivo en conocimiento y requiere de habilidades específicas, así como de mano de obra intensiva, en el caso de las industrias que requieren altos insumos creativos por ejemplo el cine y el teatro. Se calcula que las industrias creativas representan entre el 2 y el $8 \%$ del empleo de la mayoría de los países (UNESCO, 2013).

Desde un aspecto social y cultural, la Comisión Interamericana de la Cultura de la OEA, considera que las industrias culturales contribuyen al combate de la desigualdad, la pobreza y a la regeneración de las ciudades como espacios seguros; además de que representan una opción de empleo para grupos vulnerables o marginados. Son una fuente de intercambio, innovación y creatividad y representan un patrimonio común de la humanidad. Fortalecen la identidad, la creatividad y el dialogo intercultural. Además, traen consigo una ciudadanía democrática y plural (SELA, 2011).

Por último, las industrias creativas contribuyen al desarrollo sostenible, no sólo entendido en pro del medio ambiente, lo cual también es cierto si se considera que su principal insumo es intangible y depende en gran medida de la industria pesada, sino en el sentido de que el capital cultural debe ser preservado, al igual que los recursos naturales.

A pesar de que las industrias creativas varían mucho de país en país, se pueden identificar ciertas características que predominan en estos sectores. Con respecto a su estructura organizacional, una importante proporción del empleo en estos sectores suele ser por cuenta propia, es decir, son artistas o productores independientes; $y$ en el caso de las empresas establecidas, existe un predominio de la pequeña y mediana empresa. Sin embargo, en gran parte de estas industrias, como es el cine, existen corporaciones globales de gran escala que suelen tener practicas oligopólicas, esto sucede debido a que muchas de las industrias culturales tienen economías de escala. Estas empresas tienden a predominar sobre los mercados, por ende, excluyendo las expresiones culturales locales.

Otra característica de las industrias creativas o culturales es que sufren de la ineficiencia que los economistas llaman "la tragedia de los bienes comunales", ya que su consumo es no rival y 
no exclusivo. Es decir, que el uso por una persona no excluye la utilización del resto, por lo que son accesibles para un número ilimitado de personas. Por esta razón, los bienes culturales al ser parte de la identidad de un país, suelen ser concebidos como públicos.

Por último, el costo de producir un bien cultural o creativo suele ser alto, principalmente por el tiempo que puede llevar su producción, mientras que reproducirlo tiene un costo bajo, lo que lleva al surgimiento de mercados informales. Por lo anterior, los estudios sobre la contribución de las industrias creativas tienden a estar subestimados al no considerar un registro completo de estas actividades, su comercialización o la población a la que emplean.

\section{La contribución económica de la} $\frac{\text { economía creativa en }}{\text { países de renta media }^{2}}$

Cada vez se reconoce más la importancia de las industrias culturales y creativas en el desarrollo económico de un país, por lo que recientemente se ha desarrollado una creciente literatura que busca medir su impacto en el desarrollo de una economía. Si bien los resultados varían dependiendo del modelo que se utilice, todos concuerdan en la importancia que tiene este sector sobre la economía a nivel mundial y el papel estratégico que representan para los gobiernos.

La OMPI es el organismo que más se ha interesado en medir la aportación económica de este sector, entendido como los bienes protegidos por la propiedad intelectual, a la economía en diferentes países. Sin entrar en tantos detalles, basta con mencionar que la OMPI considera cuatro grupos de industrias: 1) industrias principalmente relacionadas con el derecho de autor o clave, que son las que se dedican íntegramente a la creación, producción y fabricación, interpretación o ejecución, radiodifusión, comunicación y exhibición, o distribución y venta de obras y otro material protegido; 2) las industrias interdependientes, que son las dedicadas a la producción y venta de equipos cuya función consiste en facilitar la creación de obras protegidas; 3) industrias que dependen parcialmente del derecho de autor, es decir, que una parte de las actividades está relacionada con las obras protegidas; 4) industrias de apoyo, que facilitan la radiodifusión, la comunicación, la distribución o la venta de obras que dependen parcialmente del derecho de autor.

En el presente estudio se seleccionaron 10 países de renta media, para lo cual se utilizó la definición del Banco Mundial para distribuir los países según su nivel de ingresos. Dicho organismo clasifica las economías, según el ingreso nacional bruto (INB) per cápita, en: ingreso bajo, medio-bajo, medio-alto y alto. La selección de países analizados se encuentra en niveles de ingreso medio-bajo y medio-alto, es decir, que su INB per capita va de los $\$ 1,045$ a los $\$ 12,746$ dólares.

Esta selección pretende cubrir diferentes regiones y países cuya aportación a la economía varíe en términos de valor agregado y empleo, con el fin de evaluar si la legislación muestra distintos comportamientos que puedan explicar las diferencias en la contribución. Se eligieron 4 países de Latinoamérica, 3 de Europa y Asia Central y 3 de Asia del Este y Pacífico. Dentro de cada subgrupo se eligió un país con una aportación alta, otra media y otra baja.

A continuación se presenta una tabla con la contribución al PIB, al empleo y a la productividad laboral de los países seleccionados, según la OMPI:

2 En este apartado, todos los datos proporcionados corresponden al estudio realizado por la OMPI en Studies on the Economic Contribution of the Copyright Industries (2014) o a los estudios individuales realizados por el mismo organismo titulados The Economic Contribution of Copyright-Based Industries de cada país, a menos que se indique lo contrario. 


\section{Contribución económica}

\begin{tabular}{|c|c|c|c|}
\hline PAís & PIB & EMPLEO & $\begin{array}{c}\text { PRODUCTIVIDAD } \\
\text { LABORAL }\end{array}$ \\
\hline Hungría & $7.42 \%$ & $7.28 \%$ & $102 \%$ \\
\hline China & $6.37 \%$ & $6.52 \%$ & $98 \%$ \\
\hline Panamá & $6.35 \%$ & $3.17 \%$ & $200 \%$ \\
\hline Rumania & $5.55 \%$ & $4.19 \%$ & $132 \%$ \\
\hline Filipinas & $4.82 \%$ & $11.10 \%$ & $43 \%$ \\
\hline México & $4.77 \%$ & $11.01 \%$ & $43 \%$ \\
\hline Argentina & $4.70 \%$ & $3.00 \%$ & $157 \%$ \\
\hline Tailandia & $4.48 \%$ & $2.85 \%$ & $157 \%$ \\
\hline Ucrania & $2.85 \%$ & $1.90 \%$ & $150 \%$ \\
\hline Perú & $2.67 \%$ & $4.50 \%$ & $59 \%$ \\
\hline
\end{tabular}

GRÁFICA 1: VALOR AGREGADO POR TIPO DE INDUSTRIA

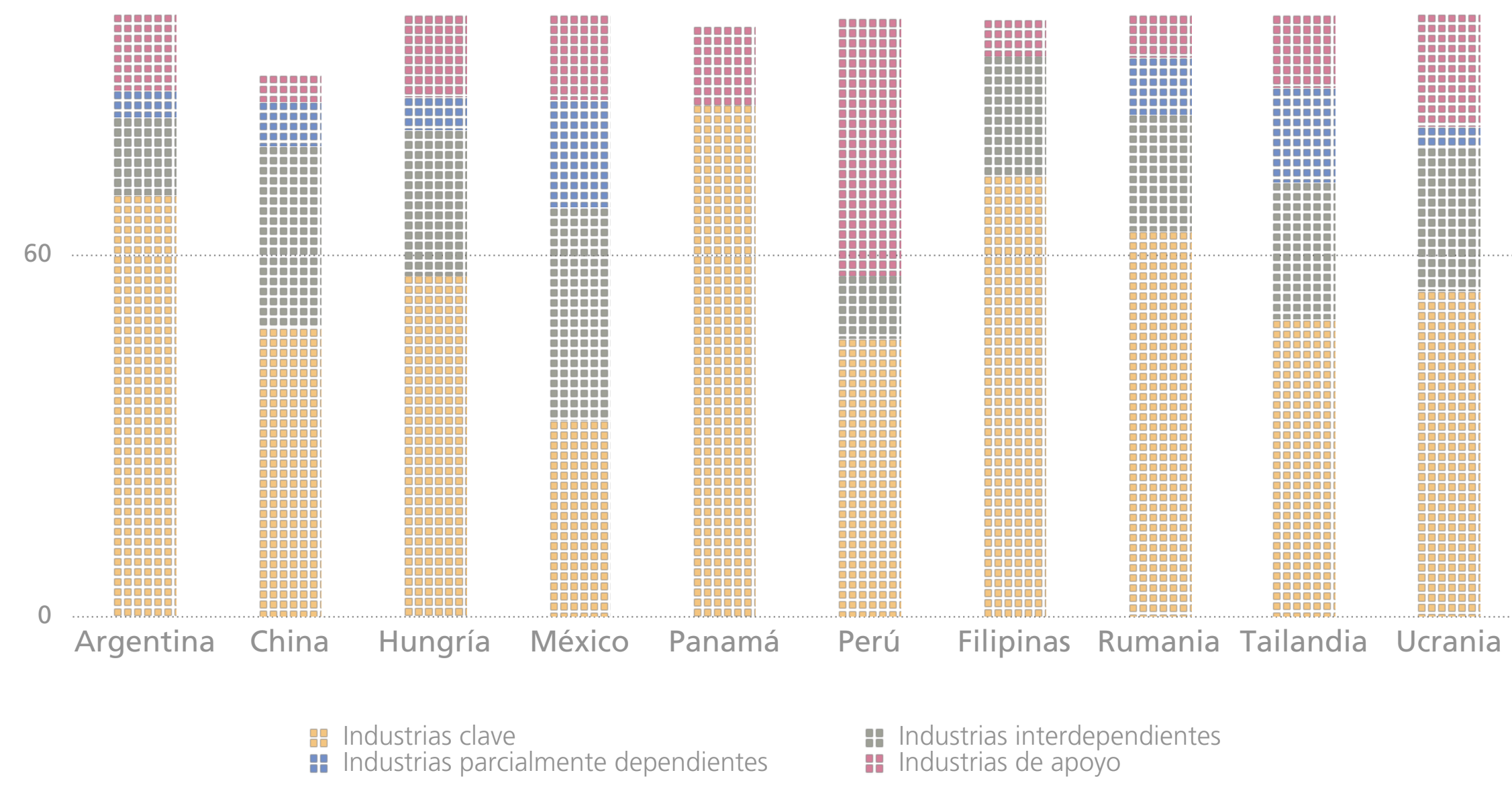




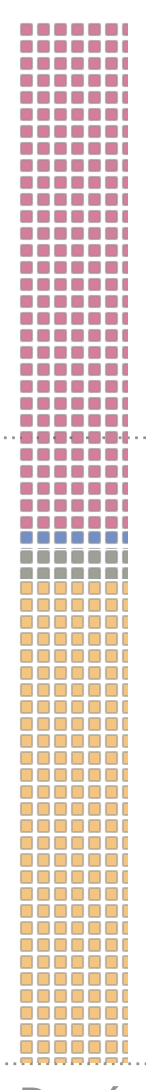

Perú

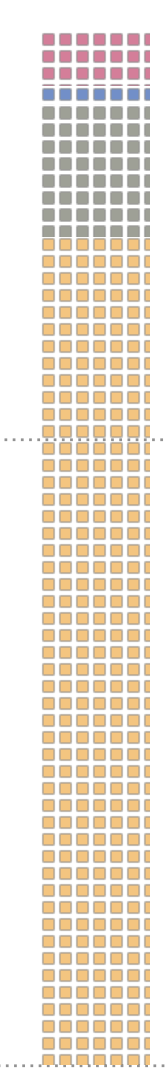

Filipinas
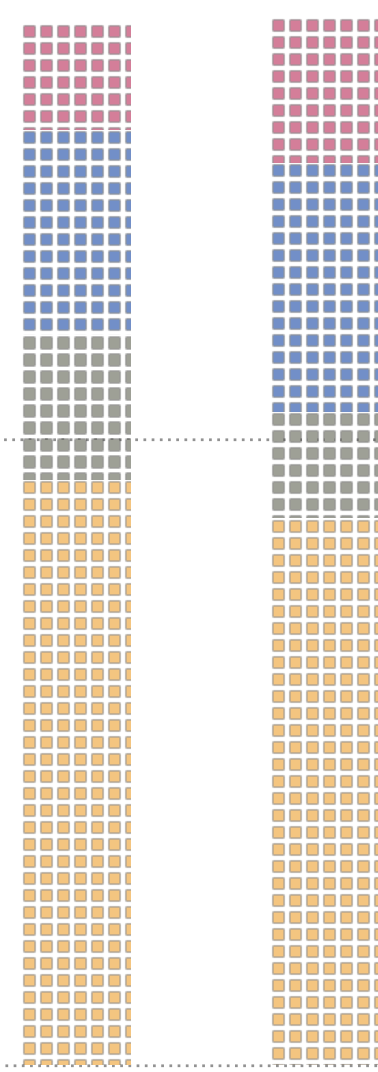

Rumania Tailandia

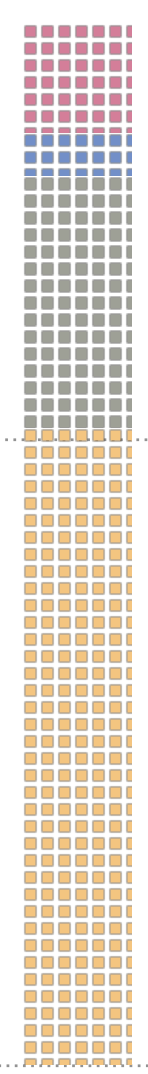

Ucrania
몸 Industrias clave

* Industrias parcialmente dependientes
\# Industrias interdependientes

Hit Industrias de apoyo

Fuente: Cálculos propios a partir de OMPI, 2014
Como se puede apreciar en la tabla anterior, en países como Hungría, China y Panamá las industrias protegidas por el derecho de autor contribuyen con más del $6 \%$ del PIB. Por el contrario, en Perú y Ucrania contribuyen con menos del $3 \%$. En términos de empleo, destaca el caso de Filipinas y México, siendo ambos países los dos que más contribuyen al empleo de los 40 estudiados por la OMPI. En dichos países, las industrias culturales aportan más del $11 \%$ de empleo del país, es decir, que 1 de cada 10 mexicanos o filipinos se emplea en sectores relacionados con las industrias protegidas por el derecho de autor. En el caso de los países Europeos seleccionados, la productivi- dad laboral es mayor a 100, lo que significa que el valor agregado que generan es mayor que el porcentaje de empleo que representan. En este sentido, destacan Tailandia y Argentina, pero sobretodo, Panamá.

En 2008, en Argentina, mientras que el PIB tuvo un crecimiento del $6.3 \%$, la economía creativa aumentó $9.3 \%$. Argentina destaca por el alto porcentaje que representan las industrias clave, tanto en contribución al PIB como en empleo. Ambas representan más del $70 \%$ del total de las industria creativas. Siendo especialmente relevantes dentro de éstas, la industria editorial y prensa ( $25 \%$ del 
valor agregado de las industrias clave), servicios de computación $(21 \%)$ y servicios de transmisión de televisión (17\%). Esto podría explicar la alta productividad laboral con la que cuenta la economía creativa dentro de este país, debido a que su contribución se concentra en actividades creativas que generan mayor valor agregado. Para el año 2008, el empleo en las industrias creativas en general registró un total de 532,000 puestos de trabajo, de los cuales 361,000 fueron generados por las industrias creativas clave. Cabe destacar que, con respecto a algunas industrias creativas clave como en el caso concreto de la industria del software, el gobierno argentino promovió un esquema de incentivos encaminados al desarrollo de empresas de software nacionales.

De igual forma, Panamá y Filipinas muestran una alta concentración del valor agregado en las industrias clave ( $85 \%$ y $73.2 \%$, respectivamente). Sin embargo, en el caso de Panamá, a diferencia de Filipinas y Argentina, el empleo en estas industrias no representa un alto porcentaje. En Panamá, a pesar de que la industria editorial y de prensa generan el mayor porcentaje de empleos y valor agregado, la mayor productividad laboral se da en Música, Teatro y Ópera debido a que mientras que representan únicamente el $6.45 \%$ del empleo dentro de las industrias clave, generan el $23.35 \%$ del valor agregado. En Filipinas, los sectores editorial y literario representan el $56 \%$ del empleo y $56 \%$ del valor agregado que generan las industrias creativas. A nivel nacional, estos sectores representan el $2.13 \%$ del PIB, sin embargo, la tasa de productividad más alta se registró en los sectores de radio y televisión, que conjuntamente con los sectores de la música, ópera y teatro, empresas de software y bases de datos, aportaron más de $1 \%$ del PIB.

En Panamá, el desarrollo de una serie de industrias terciarias ligadas con la prestación de diversos servicios, aunado a la introducción de nuevas tec- nologías en años recientes, emplea a buena parte de la población económicamente activa en el país.

México es un país con una tradición cultural sumamente rica, valorada y reconocida local e internacionalmente. Además, ha dedicado especial atención al impacto que en su economía generan las industrias creativas, por lo que se han tomado medidas para incentivar el apoyo y crecimiento de micro, pequeñas y medianas empresas que puedan contribuir al crecimiento del sector, la creación de empleos y de la economía en general. Con respecto a las industrias clave, México es uno de los países de América Latina que cuentan con una industria editorial más prósperas de la región, en cuanto a producción y distribución. En términos de infraestructura de la industria editorial, las pequeñas empresas editoriales y las librerías tradicionales han sido reemplazadas por grandes consorcios y nuevos esquemas de distribución a través de medios digitales como el Internet. En términos económicos, de acuerdo con el estudio de la OMPI, la industria de prensa y literatura es, sin duda alguna, la más importante dentro de la categoría de industrias creativas clave. En 2003, la industria contaba con 198,467 empleos.

A diferencia del resto de los países donde las industrias claves representan en promedio el $60 \%$ del valor agregado de las industrias creativas, México destaca debido a que es el país de la muestra donde el porcentaje que constituyen las industrias clave es el más bajo y la contribución de las industrias interdependientes es de los más altos, dentro de los cuales destacan las industrias de electrónicos, manufactura de equipo de cómputo y papel, siendo esta última la que mayor proporción de los empleos genera. Esto podría explicar la baja productividad que presentan las industrias creativas en México, ya que existe una especialización en trabajos de manufactura que son menos intensivos en conocimiento y no en empleos creativos que generan mayor valor agregado. 
En Ucrania, las industrias clave generan más del $60 \%$ del empleo de las industrias creativas, sin embargo, generan menos el $54 \%$ del valor agregado, resultando en una baja productividad dentro de este sector.

A pesar de que el desarrollo de las industrias creativas ha sido clave en el crecimiento de algunos países asiáticos, su valor no es reconocido de manera general. Sin embargo, existen países que consideran a las industrias creativas como estratégicas en su desarrollo, tal es el caso de China y Filipinas. En los últimos cinco años, en China se ha presentado un boom de las industrias creativas. En este país, las industrias clave contribuyeron con el $48.2 \%$ del total de los empleos generados por el sector. En cuanto a contribución económica a nivel general, las industrias creativas generaron en el año 2006, un total de 7.63 millones de empleos, lo que constituye el $6.5 \%$ del empleo total a nivel nacional.

En cuanto al comercio exterior, según la UNCTAD, China, México y Tailandia, se encuentran entre los mayores exportadores de bienes culturales. Del 2000 a 2008, China se convirtió en una de las economías líderes en el mercado mundial de bienes creativos debido a la riqueza de su diversidad cultural y su capacidad de producir una equilibrada mezcla entre lo tradicional y de alta tecnología, pero también debido a una clara política pública encaminada a cumplir este objetivo. En 2008, el $20.84 \%$ del total de exportaciones chinas fueron de bienes culturales y creativos, siendo por mucho el país con mayor porcentaje de exportación. Por su parte, México, Tailandia y Argentina se encuentran entre los mayores exportadores de productos audiovisuales de los países en desarrollo (UN, 2010).

Existe un amplio debate de las cifras sobre aportación económica. Por ejemplo, Piedras (2010) estima que en México la aportación al PIB, tan sólo de las industrias culturales, es de $6.7 \%$. Conside- rando a la economía sombra, tan sólo debajo de sectores como la maquila, petróleo y turismo. Si bien este debate tiene una gran relevancia, como se comentó anteriormente, el presente estudio busca hacer un comparativo entre países con el fin de evaluar si las diferencias pueden ser explicadas mediante la regulación existente en cada país en materia de derechos de autor. Para lo anterior, a continuación se analizará dicha regulación, en el ámbito nacional e internacional.

\section{La requlación de la economía creativa: ámbito nacional e internacional}

La regulación en materia de propiedad intelectual permite otorgarle a los bienes creativos y culturales la característica de "propiedad" con todas las implicaciones económicas que esto conlleva, como la capacidad de comercializarlo. La legislación en materia de derecho de propiedad intelectual incentiva la producción de bienes culturales y creativos al asignarle un valor a la inversión de tiempo necesario en producirlas; además, evita la competencia imperfecta, causada a partir del dominio por parte de corporativos globales y reduce los efectos de las ineficiencias en el mercado al tratarse de bienes que son concebidos como públicos. Una legislación efectiva en materia de derechos de autor es crucial para reducir la piratería. Por último, la regulación en materia de derechos de autor es clave, ya que promueve la creatividad, innovación, progreso social y tecnológico. Los bienes culturales y creativos deben legislarse, no sólo por su valor económico, sino por su interés social y cultural al ser un vehículo de cohesión social que crea identidad y garantiza la diversidad; además de que crean externalidades que son be- 
néficas para toda la población, como es el caso de la Investigación y desarrollo (R\&D). Por último, las políticas públicas deben de promover el empleo y una justa remuneración por éste, así como la asignación eficiente de recursos, la sana competencia y la distribución equitativa del ingreso.

Como consideraciones preliminares, es importante tomar en cuenta que en los países estudiados, la propiedad intelectual en sentido amplio, se divide en dos grandes ramas: la propiedad industrial y la propiedad intelectual, en sentido estricto.

La propiedad industrial comprende todas aqueIlas figuras que se relacionen en forma primordial con el comercio, la industria y las ciencias; consistentes en aquellas prerrogativas que sin constituir monopolios, el Estado otorga en forma temporal $y$ en exclusiva en favor de los inventores y perfeccionadores de alguna mejora, aplicable a la industria o comercio, comprendiendo principalmente: Las invenciones (patentes, modelos de utilidad, diseños industriales y esquemas de trazado de circuitos integrados), los signos distintivos (marcas, avisos comerciales, nombres comerciales y denominaciones de origen), los secretos industriales, las variedades vegetales, los procedimientos administrativos y las franquicias.

La propiedad intelectual, en sentido estricto, comprende todas aquellas expresiones estéticas de la creatividad humana, ligadas en forma primordial con las artes y la cultura; aquellos privilegios que el Estado otorga en forma temporal y exclusiva, en favor de los autores y artistas para la producción de sus obras, comprendiendo principalmente: Los derechos de autor y los derechos conexos de artistas intérpretes o ejecutantes; editores de libros; productores de fonogramas, productores de videogramas y organismos de radiodifusión.

Existen otros derechos, en materia de propiedad intelectual, como puede ser en el caso de México las reservas de derechos o el derecho a la imagen de las personas, sin embargo no serán abordados en esta investigación. En lo sucesivo, nos referiremos a esta rama únicamente como propiedad intelectual. Como se mencionó anteriormente, el presente estudio se enfoca principalmente en la regulación sobre derechos de autor, ya que es la que mayor parte abarca de la economía creativa, aunque también se examinan de manera general otras legislaciones.

\section{La regulación internacional de las industrias creativas}

Por definición, las industrias creativas y, en específico el derecho de autor, tienen un carácter preponderantemente local, sin embargo, gran parte de la regulación de estas industrias se rige bajo los tratados internacionales, al menos en cuanto a los derechos de autor. Existe una amplia literatura que revisa la regulación internacional en materia de derechos de autor (Caballero, 2006), por lo que en el presente artículo únicamente se esbozará la legislación más importante en esta materia.

El primer instrumento para legislar los derechos de autor a nivel internacional fue el Convenio de Berna, firmado en Suiza en 1886, con el objetivo de unificar la producción en el extranjero de las obras protegidas por el derecho de autor. Por lo anterior, el convenio establece dos principales cuestiones: el trato nacional que se le dará a las obras en los Estados miembros, de la misma forma en que se protegen a las obras nacionales y los derechos y protección mínima que los Estados deben proporcionar a las obras. El Convenio establece las obras y derechos que deberán de ser protegidos, así como quién detenta la titularidad de los derechos y la duración mínima de los mismos. 


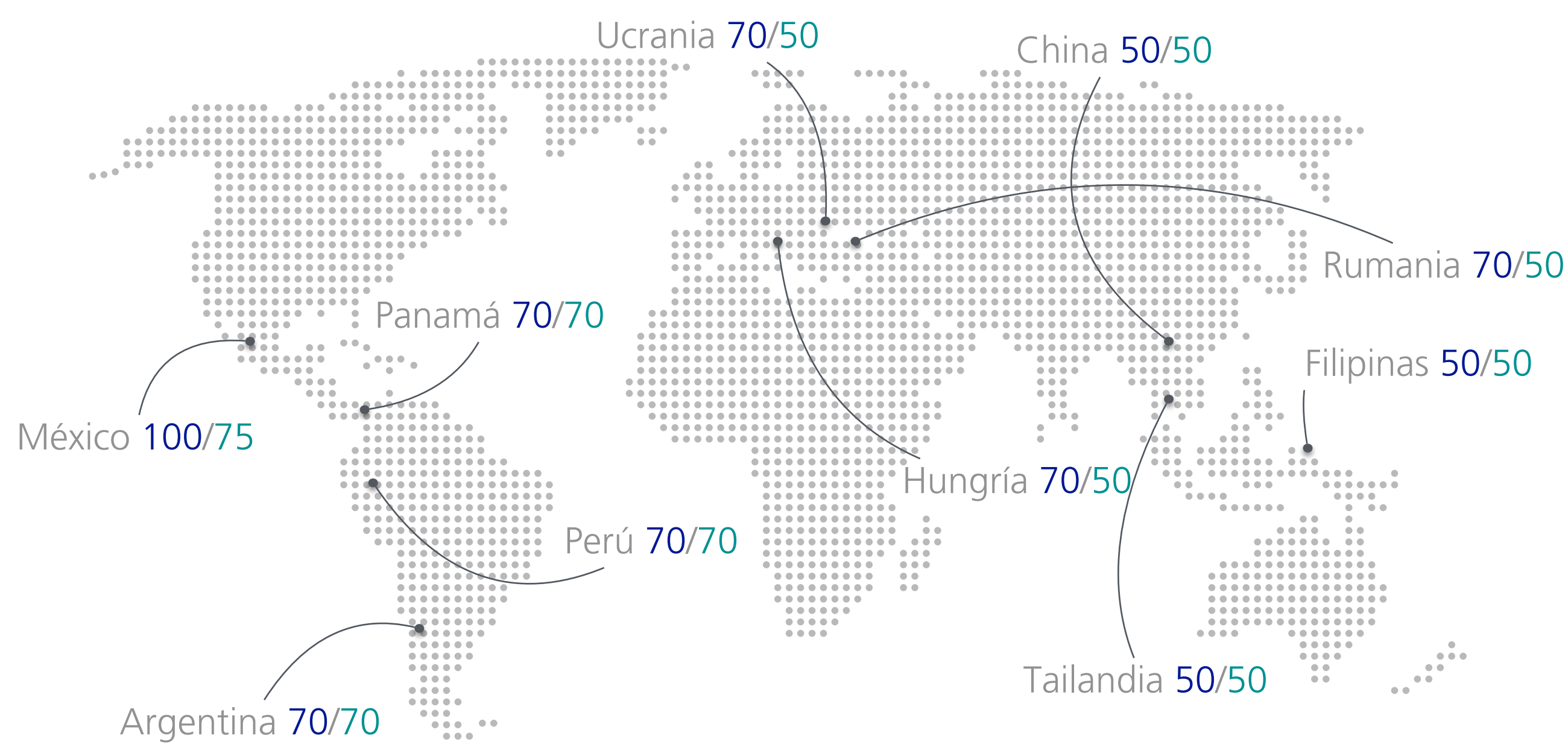

Fuente: Leyes de los países seleccionados (Ver Referencias)

Posteriormente, con la finalidad de regular la copia no autorizada de fonogramas y debido al avance tecnológico, se firmó en 1928 la Convención de Roma, que protege los derechos conexos. La Convención establece que todos los Estados que pretendan adherirse deben ser parte de la Convención de Berna. Al igual que el convenio de Berna, esta convención establece el trato nacional a los artistas intérpretes o ejecutantes, los productores de fonogramas y los organismos de radiodifusión. Además, le concede a los artistas intérpretes o ejecutantes la posibilidad de impedir la radiodifusión y la comunicación al público de sus interpretaciones o ejecuciones en vivo, la grabación de una interpretación o ejecución no fijada y la reproducción de una fijación sin el consentimiento del artista intérprete o ejecutante. Además, concede a los productores de fonogramas el derecho de autorizar o prohibir la reproducción directa o indirecta de sus fonogramas. Por último, le otorga el derecho a autorizar o prohibir a los organismos de radiodifusión la retransmisión simultánea de sus emisiones, la fijación de sus emisiones, la reproducción de fijaciones no autorizadas de sus emisiones y la comunicación al público de sus emisiones de televisión. Además, establece el plazo mínimo de protección de los derechos de los intérpretes y ejecutantes, que es de 20 años.

Los convenios y acuerdos siguientes se basan en los mismos principios pero buscan adaptarse a las condiciones del momento en que fueron firmados. De esta forma, el Convenio para la protección de los productores de fonogramas contra la reproducción no autorizada de sus obras, surgió del aumento en la piratería a finales de los años sesenta derivado del avance tecnológico en los métodos de grabación y busca prote- 
ger a los productores de fonogramas en contra de la producción de copias así como su importación no consentida. Por su parte, el Convenio de Bruselas sobre la distribución de señales portadoras de programas transmitidos por satélite surgió debido a la multiplicación de satélites en las telecomunicaciones internacionales y su principal objetivo es impedir la distribución de señales portadoras de programas y transmitidas mediante satélite, por distribuidores a quienes esas señales no estén destinadas.

No es hasta veinte años después, al darse cuenta de la importancia, no sólo cultural sino económica de las industrias creativas, que en el marco de la Organización Mundial del Comercio, se firma el Acuerdo sobre los aspectos de los derechos de propiedad intelectual relacionados con el comercio (TRIPS, por sus siglas en inglés). El Acuerdo establece que los países miembro deben de cumplir con el Convenio de Berna en términos generales y que los programas de computadora o software y las compilaciones de datos deben de estar protegidos por el derecho de autor. Es importante mencionar que a diferencia del Convenio de Berna, el Acuerdo no crea derechos morales, por lo que sigue una línea más similar al modelo anglosajón que al continental.

Por último, con el objetivo de establecer una "agenda digital", en 1996 la OMPI elaboró dos tratados, uno sobre derechos de autor y otro sobre interpretación o ejecución y fonogramas. Ambos tratados extienden el derecho de reproducción al almacenamiento de obras en sistemas digitales, establecen las limitaciones y excepciones aplicables en el medio digital y las medidas tecnológicas de protección. Ambos instrumentos tambièn reconocen el derecho de los autores, artistas intérpretes o ejecutantes y de los productores de fonogramas a autorizar la transmisión directa de sus obras, de sus interpretaciones o eje- cuciones fijadas y de sus fonogramas, según sea el caso. Además, otorga a los autores un derecho exclusivo de distribución, en el sentido de autorizar la puesta a disposición del público de originales y copias de sus obras. Otorga un derecho a los autores a autorizar el alquiler comercial de programas de ordenador, obras cinematográficas y obras contenidas en fonogramas.

En cuanto a otros tratados internacionales referentes a la economía creativa, pero no necesariamente vinculados a los derechos de autor, podemos mencionar la Convención sobre la protección y la promoción de la diversidad de las expresiones culturales de la UNESCO, la cual entró en vigor el 18 de marzo de 2007. Esta Convención fue un primer intento para proteger la diversidad cultural de los países y tiene, entre otros, los objetivos de proteger y promover la diversidad de las expresiones culturales; fomentar el diálogo entre culturas a fin de garantizar intercambios culturales más amplios y equilibrados; promover el respeto de la diversidad de las expresiones culturales; reafirmar la importancia del vínculo existente entre la cultura y el desarrollo para todos los países, en especial los países en desarrollo; reiterar los derechos soberanos de los Estados a conservar, adoptar y aplicar las políticas y medidas que estimen necesarias para proteger y promover la diversidad de las expresiones culturales en sus respectivos territorios; así como fortalecer la cooperación y solidaridad internacionales.

Por último, también existe una serie de acuerdos bilaterales o regionales que buscan establecer relaciones internacionales con el fin de promover, proteger y difundir las obras culturales o creativas, como son los acuerdos y convenios culturales y educativos, los tratados para la protección de los derechos de autor y los convenios de coproducción cinematográfica. Estos últimos, además de promover las cinematografías de los estados firmantes en el resto de los países, otorgan el reconocimiento de obra nacional a las producciones realizadas 
en coproducción a fin de que tengan acceso a los mecanismos de apoyo y cumplimiento de cuotas en ambos países. Estos acuerdos han sido cruciales principalmente en países que por su tamaño no cuentan con los fondos suficientes para la producción como es el caso de Europa del Este. ${ }^{3}$

Si bien los convenios y acuerdos internacionales permiten un incremento en el comercio, así como una expansión en el mercado de los bienes culturales y creativos, también puede afectar de manera considerable la producción local, por lo que diversos países han adoptados medidas especiales y exenciones, con el fin de proteger las expresiones locales y evitar la estandarización. A lo anterior se le conoce como al "excepción cultural". Por ejemplo, la Unión Europea se ha negado liberalizar el sector audiovisual, desarrollando además mecanismos de protección como son el establecimiento de cuotas de transmisión.

\section{La regulación nacional de las industrias creativas.}

Como ya se mencionó, las industrias culturales y creativas se regulan de manera local y los diversos acuerdos internacionales establecen un marco general y condiciones mínimas que deben cumplirse para su protección, sin embargo, dejan la libertad a cada país de regular las cuestiones específicas en materia de derechos de autor. A pesar de esto, las leyes nacionales son muy similares en casi todos los países y se pueden dividir principalmente en dos modelos. Los que siguen el modelo continental de derechos de autor, establecido por primera vez en Francia o los que siguen el modelo anglosajón del copyright. La principal diferencia entre estos dos radica en el lugar que le dan al autor como el principal detentor de los derechos. Mientras que el derecho de autor reconoce a éste como el creador de la obra, el copyright aplica hasta el momento en que la obra es publicada y se refiere al derecho de copia. Generalmente, el modelo de derechos de autor aplica en países cuyo sistema se basa en el derecho civil, el cual aplica a todos los países seleccionados.

Posteriormente, una de las diferencias entre un país y otro se basa, de manera general, en el plazo de protección de los derechos de autor para posteriormente pasar al dominio público. En la mayoría de los países el plazo de protección de los derechos patrimoniales se considera a partir de la muerte del autor y en el caso de los derechos conexos o relacionados desde su publicación o ejecución. A continuación se presenta una tabla con el número de años que la legislación establece para la protección de los derechos patrimoniales y conexos de los países seleccionados:

En gran parte de Latinoamérica no se ha reconocido el papel estratégico que tiene la economía creativa y, en consecuencia, las políticas públicas son concebidas desde la contribución cultural y de patrimonio que tienen estas industrias. Las políticas suelen ser más asistencialistas, dirigidas a apoyar la producción con fines culturales como incrementar la diversidad y preservar la identidad del país. Sin embargo, existen excepciones como Argentina y, en años recientes, México.

Argentina ha adoptado el término de industrias creativas y ha sido ampliamente estudiado. Cuenta con un marco jurídico que, aunque se encuentra rezagado en algunos aspectos, también se ha ido actualizando y adaptando conforme a los cambios que implican los avances tecnológicos, el surgimiento de nuevos formatos y medios de

3 En el Anexo 1 se presenta un cuadro donde se puede apreciar los Acuerdos y Convenios mencionados a los cuales se encuentran adheridos los países seleccionados. 
comunicación, así como el reconocimiento de los derechos de otros participantes en su sector creativo, entre otras innovaciones. Un ejemplo de esto se puede observar en la industria audiovisual de este país, ya que recientemente pasaron de una ley de cine a una ley del audiovisual adaptando la legislación a los nuevos métodos de producción, distribución, exhibición, transmisión, comercialización y consumo.

Al igual que en México y otros países, la administración en forma colectiva o de sociedades de gestión de los derechos de propiedad intelectual en Argentina es bastante amplio, por considerarse una alternativa eficiente para la reducción de costos derivados del manejo de derechos de autor y otros derechos de propiedad intelectual, incluyendo la protección, mantenimiento y cobro por la explotación de derechos de autor, derechos conexos y otros derechos de propiedad intelectual. En el caso de Europa del Este, un problema común entre los países en desarrollo ha sido que muchas de las actividades culturales pasaron de ser propiedad del Estado a empresas privadas. Ucrania es un país cuya legislación en materia de propiedad intelectual hace unos pocos años era relativamente nueva, limitada en diversos aspectos, cuya formación y modificaciones se fueron desarrollando al mismo tiempo que se estaría desarrollando un Estado constitucional. En un principio, la legislación de Ucrania en materia de derechos de propiedad intelectual fue prácticamente un componente de la legislación civil. Como otros países que también dejaron de ser repúblicas socialistas de la antigua Unión Soviética, en el caso de Ucrania se requirió de considerables esfuerzos y de apoyo de expertos, para que se fuera implementando un marco jurídico que comenzara, entre otros aspectos, por reconocer y respetar en forma paulatina los derechos que derivan del derecho de autor y de otros aspectos y derechos de propiedad intelectual en favor de creadores de obras, intérpretes, etc.
Hoy en día, después de una serie de avances en cuanto a modificaciones a su actual marco jurídico en la materia, derivado de la implementación de una serie de esquemas y políticas; aunado a la celebración de diversos tratados internacionales en materia de propiedad intelectual, Ucrania cuenta con un marco jurídico en la materia bastante más avanzado, que en su momento fue muy bien recibido por países de la Unión Europea y la OMPI, que incorpora las disposiciones comunes de los tratados internacionales, alcanza los estándares de sistemas jurídicos avanzados de diversos países desarrollados e incorpora esquemas de oportunidad para el desarrollo y crecimiento de industrias creativas relacionadas con propiedad intelectual. Como ya se mencionó, en el caso de los países asiáticos, destaca China que ha tenido un importante desarrollo debido a una clara intención por parte del gobierno de explotar el potencial de las industrias creativas como impulsor de desarrollo. A partir de una combinación de inversión, tecnología y creatividad y de políticas multidisciplinarias, que incluía a los ministerios de comercio, cultura, ciencia y tecnología, información y educación, China ha logrado posicionarse como una de las industrias líderes en sus industrias creativas (UN, 2008).

Al igual que China, Tailandia ha adoptado estrategias dirigidas a incrementar la participación de las industrias creativas. El gobierno tailandés estableció una ruta definida para desarrollar la economía creativa, convirtiéndolo en un sector prioritario en el Plan Nacional de Desarrollo Económico y Social.

Por su parte, las cuestiones de propiedad intelectual en Tailandia han cobrado mucha mayor relevancia en los años recientes. Prueba de ello, es que en los últimos años se han promulgado siete distintas leyes especiales en diferentes temas de propiedad intelectual, teniendo como objetivo 
CUADRO 3: ORgANISMOS COMPETENTE Y LEY DE DERECHOS DE AUTOR

\begin{tabular}{|c|c|c|c|c|}
\hline País & $\begin{array}{l}\text { Principal Organismo } \\
\text { COMPETENTE }\end{array}$ & LEY & $\begin{array}{l}\text { AÑo DE } \\
\text { PROMULGACIÓN }\end{array}$ & $\begin{array}{l}\text { ÚLTIMA } \\
\text { REFORMA }\end{array}$ \\
\hline Argentina & $\begin{array}{c}\text { Dirección Nacional del } \\
\text { Derecho de Autor }\end{array}$ & $\begin{array}{l}\text { Ley 11.723 Ley de Propiedad } \\
\text { Intelectual }\end{array}$ & 1933 & 2009 \\
\hline China & $\begin{array}{l}\text { Administración Nacional del } \\
\text { Derecho de Autor }\end{array}$ & Ley del Derecho de Autor. & 1990 & 2010 \\
\hline Filipinas & $\begin{array}{l}\text { Oficina de Propiedad } \\
\text { Intelectual de Filipinas } \\
\text { (IPOPHIL) }\end{array}$ & $\begin{array}{l}\text { Código de Propiedad } \\
\text { Intelectual. }\end{array}$ & 1997 & 2013 \\
\hline Hungría & $\begin{array}{l}\text { Oficina de la Propiedad } \\
\text { Intelectual }\end{array}$ & $\begin{array}{c}\text { Ley No LXXVI sobre Derecho } \\
\text { de Autor }\end{array}$ & 1999 & 2007 \\
\hline México & $\begin{array}{l}\text { Instituto Nacional del } \\
\text { Derecho de Autor } \\
\text { (INDAUTOR) }\end{array}$ & $\begin{array}{c}\text { Ley Federal del Derecho de } \\
\text { Autor }\end{array}$ & 1996 & 2014 \\
\hline Panamá & $\begin{array}{l}\text { Dirección Nacional de } \\
\text { Derecho de Autor }\end{array}$ & $\begin{array}{l}\text { Ley } 64 \text { Sobre Derecho de } \\
\text { Autor y Derechos Conexos }\end{array}$ & 2012 & 2012 \\
\hline Perú & $\begin{array}{l}\text { Instituto Nacional de Defensa } \\
\text { de la Competencia y de la } \\
\text { Protección de la Propiedad } \\
\text { Intelectual (INDECOPI) }\end{array}$ & $\begin{array}{c}\text { Ley Sobre Derechos de } \\
\text { Autor. (Decreto Legislativo } \\
\text { 822) }\end{array}$ & 1996 & 2005 \\
\hline Rumanía & $\begin{array}{l}\text { Oficina de Derechos de } \\
\text { Autor }\end{array}$ & $\begin{array}{l}\text { Ley No } 8 \text { sobre el derecho de } \\
\text { autor y derechos conexos }\end{array}$ & 1996 & 2006 \\
\hline Tailandia & $\begin{array}{l}\text { Departamento de Propiedad } \\
\text { Intelectual (DIP) }\end{array}$ & $\begin{array}{c}\text { Ley de Derecho de Autor B.E. } \\
2537\end{array}$ & 1994 & 1994 \\
\hline Ucrania & $\begin{array}{l}\text { Servicio Estatal de Propiedad } \\
\text { Intelectual de Ucrania }\end{array}$ & $\begin{array}{l}\text { Ley de Protección de los } \\
\text { Derechos de Autor y } \\
\text { Derechos Conexos }\end{array}$ & 1993 & 2003 \\
\hline
\end{tabular}

primordial, el de estimular la creatividad y las invenciones y asimismo, el de asegurar que los beneficios que se pueden obtener de los derechos de propiedad intelectual sean debidamente reconocidos.

Desde los últimos años, el gobierno de Tailandia promovió la implementación de una estrategia para transformar a Tailandia en una economía creativa. Se creó el Comité Nacional de Política de Economía Creativa, organismo que conjuntamente con otras entidades, ha dado inicio a una serie de proyectos con miras a fortalecer las capacidades de las industrias creativas en el país y entre otras medidas, solicitó la participación de organizaciones y personalidades de expertos para la implementación de estudios y análisis con el objeto de determinar el impacto que las industrias creativas en el país han tenido para distintos sectores y para identificar las áreas de oportunidad, con las cuestiones en que sea necesario implementar cambios.

Filipinas es un país que ha estado realizando una serie de esfuerzos, desde años recientes, y procurado desarrollar políticas para proveer una adecuada protección y defensa de los derechos de propiedad intelectual y garantizar mejores con- 


\begin{tabular}{|c|c|c|c|c|c|c|}
\hline País & $\begin{array}{l}\text { PIB PER CAPITA } \\
\text { (PPA) } 1\end{array}$ & $\begin{array}{l}\text { ÍNDICE DE } \\
\text { COMPETITIVIDAD } \\
2\end{array}$ & $\begin{array}{l}\text { EFECTIVIDAD DEL } \\
\text { GOBIERNO } 3\end{array}$ & $\begin{array}{l}\text { CONTROL DE } \\
\text { CORRUPCIÓN } 3\end{array}$ & $\begin{array}{l}\text { GLOBAL } \\
\text { INNOVATION } \\
\text { INDEX } 1 \\
\end{array}$ & $\begin{array}{l}\text { MANDATO DE } \\
\text { LEY } 3\end{array}$ \\
\hline Argentina & $18,749.30$ & 3.79 & -0.29 & -0.46 & 35.1 & -0.73 \\
\hline China & $9,844.00$ & 4.89 & -0.03 & -0.35 & 46.6 & -0.46 \\
\hline Filipinas & $4,682.00$ & 4.40 & 0.06 & -0.40 & 29.9 & -0.43 \\
\hline Hungría & $20,065.10$ & 4.28 & 0.64 & 0.29 & 44.6 & 0.56 \\
\hline México & $15,562.60$ & 4.27 & 0.31 & -0.48 & 36 & -0.58 \\
\hline Panamá & $16,658.10$ & 4.43 & 0.32 & -0.36 & 38.3 & -0.24 \\
\hline Perú & $11,123.70$ & 4.24 & -0.14 & -0.44 & 34.7 & -0.61 \\
\hline Rumania & $13,395.90$ & 4.30 & -0.07 & -0.20 & 38.1 & 0.11 \\
\hline Tailandia & $9,874.50$ & 4.66 & 0.21 & -0.33 & 39.3 & -0.13 \\
\hline Ucrania & $7,423.10$ & 4.14 & -0.65 & -1.09 & 36.3 & -0.83 \\
\hline
\end{tabular}

diciones para el desarrollo de otras industrias y con ello, incentivos para atraer inversión, así como para dejar de depender de otros bienes e industrias tradicionales, para ser una economía de conocimiento y de activos intangibles. Entre otras medidas, Filipinas ha celebrado diversos tratados internacionales, tratando de adaptar su marco jurídico a las disposiciones establecidas en éstos y asegurar uno más adecuado y protección de derechos en materia de propiedad intelectual. Como se puede observar en el cuadro anterior, a excepción de Tailandia, las leyes que protegen los derechos de autor en los países seleccionados han tenido reformas en años recientes. A pesar de lo anterior, el avance tecnológico se ha dado de manera mucho más acelerada que las modificaciones a la regulación. 


\section{Instituciones, índices de legalidad $\mathbf{y}$ propiedad intelectual}

La existencia de un marco legal adecuado no garantiza el cumplimiento de los derechos de propiedad intelectual, sino que a la par se requiere de instituciones fuertes que permitan el cumplimiento de las leyes. Como se observó anteriormente, si bien cada ley tiene sus particularidades en los países estudiados, éstas no parecen explicar por sí solas las diferencias en la contribución económica que aportan las industrias creativas en cada uno de ellos, sino que se relaciona más con una cuestión de política pública, así como la fuerza de las instituciones. Con el fin de analizar lo anterior, a continuación se presentan una serie de indicadores de legalidad para los países estudiados.

El Producto Interno Bruto per cápita por paridad del poder adquisitivo muestra una correlación positiva con la contribución de las industrias protegidas por el derecho de autor. El análisis de la OMPI sugiere que existe una fuerte y positiva correlación entre la contribución de las industrias protegidas por el derecho de autor y el Índice de competitividad, es decir, que las economías más competitivas cuentan con una mayor presencia de las industrias protegidas por el derecho de autor.

De igual forma, si consideramos los indicadores del Banco Mundial relativos a la efectividad del gobierno, control de corrupción y mandato de Ley, se observa una fuerte y positiva correlación con la contribución de las industrias creativas, tanto al PIB como al empleo. Los tres indicadores van de -2.5 a 2.5 , siendo este último el mejor resultado posible. En el caso del indicador de efectividad del gobierno, es un indicador que refleja la percepción sobre los servicios públicos, la calidad del servicio civil y el grado de independencia de presiones políticas, la calidad de la formulación de políticas públicas y su implementación, así como la credibilidad del compromiso del gobierno con esas políticas. Control de corrupción refleja la percepción de la medida en que el poder público se ejerce para obtener ganancias privadas, así como el control del Estado por minorías selectas e intereses privados. Muestra que a mayor nivel de corrupción, menor certidumbre en las instituciones y menor inversión en las industrias creativas. Por último, el indicador de mandato de Ley refleja la percepción de la medida en que los agentes confían y cumplen con las reglas de la sociedad, y en particular, el grado de ejecución de contratos, derechos de propiedad, la policía y los tribunales, así como la probabilidad de delincuencia y violencia.

Según la OMPI, el índice con mayor correlación con las industrias creativas es el Índice Global de Innovación (GII, por sus siglas en inglés), el cual va de 0 a 100, siendo este último el mejor resultado posible. El GIl utiliza 81 indicadores de 143 países, con el fin de establecer un factor de innovación comparable entre países y se calcula a partir de dos subíndices: el subíndice de insumos y el de productos. El de insumos se conforma por siete pilares: instituciones, capital humano e investigación, infraestructura, sofisticación de los mercados y sofisticación de las empresas. Por su parte, el subíndice de productos se divide en dos pilares: conocimiento y productos tecnológicos y productos creativos.

El radio de eficiencia en innovación es la relación entre ambos subíndices y se refiere a cuántos productos de innovación se obtiene a partir de los insumos de innovación con los que cuenta un país. En este sentido destacan China que ocupó el segundo lugar de los 143 países estudiados, Panamá, Filipinas, Ucrania, Rumania y Hungría. China y Malasia son los únicos países de renta media que se encuentran dentro de los 25 países con un mayor GII. 
De la muestra de los países, destacan los países que fueron clasificados como "aprendices de innovación.", como se clasifica a las economías con un Gll al menos 10 por ciento más alto que sus pares por su nivel de producto interno bruto. Sólo 19 países del estudio fueron clasificados de esta forma, incluyendo China, Tailandia y Ucrania.

En cuanto a educación, como formación de capital humano, China, Argentina y Hungría, han hecho esfuerzos visibles para mantener o mejorar la calidad de sus recursos humanos mediante la educación y el aprendizaje permanente.

El GGI, muestra que México y Filipinas tienen deficiencia en empleo con conocimiento intensivo, un nivel muy bajo de capital humano e investigación, lo que explicaría la baja productividad que presentan ambos países. Por el contrario, China ha expandido el sistema de educación superior y aún más su sistema de investigación.
Con respecto a los tres países cuyas industrias creativas presentan una mayor contribución al PIB, China tiene los mayores niveles del Índice de Competitividad e Innovación, sin embargo, en los niveles del Banco Mundial de Legalidad, no cuenta con los mejores niveles. Por el contrario, Hungría cuenta con los niveles más altos en los Índices de legalidad y con muy buenos niveles en los de Competitividad e Innovación. Por último, Panamá contó con buenos niveles de Competitividad y efectividad del Gobierno, pero no tan buenos en Control de Corrupción y Mandato de Ley.

Por su parte, en los tres países cuyas industrias creativas presentan una menor contribución al PIB, se puede observar que Filipinas es el país con el menor índice de Innovación, seguido de Perú. En el caso de Ucrania es el país con peores niveles de Legalidad. 


\section{Conclusiones}

A nivel global se está modificando la forma en que consumimos, producimos, distribuimos, comercializamos los bienes creativos y culturales. Las reformas a la legislación son mucho más lentas que el avance tecnológico, por lo que no existe un marco legislativo apropiado para las características de los mercados protegidos por la propiedad intelectual actuales. Los intentos por regular la propiedad intelectual a nivel internacional en los últimos años, han fracasado debido a que bajo el argumento de proteger derechos de autor, los gobiernos buscan contar con otros tipo de atribuciones, como tener acceso a los infinitos datos que existen sobre los usuarios de internet, lo que no ha permitido avanzar en esta materia. A pesar de que urge actualizar la legislación en materia de propiedad intelectual a nivel mundial, esto no parece explicar las diferencias en los porcentajes que representan las industrias protegidas por el derecho de autor al valor agregado y empleo de cada país, sino que son el marco institucional y la legalidad los factores centrales para generar los incentivos apropiados que promuevan la innovación y la creatividad.

Queda claro el papel estratégico que tienen las industrias creativas y culturales dentro del desarrollo de un país en términos de valor agregado, empleo y comercio exterior, pero también como generadoras de bienestar y generadoras de innovación, conocimiento, identidad y patrimonio. Es necesario que los gobiernos busquen modelos novedosos que regulen la propiedad intelectual, que incentiven al consumidor a valorar los derechos de autor, respetando también la libertad en Internet y de compartir información, y que promuevan el desarrollo de las industrias culturales y creativas, como puede ser el impuesto a la copia privada, las exenciones fiscales o los créditos blandos.
Se debe generar políticas públicas que permitan evitar las ineficiencias que se presentan en el mercado de las industrias creativas, protegiendo a las industrias locales, así como promover su desarroIlo, mediante apoyos que conduzcan a empresas sostenibles en el largo plazo que no dependan únicamente del otorgamiento de subsidios por parte del Estado. El Estado debe de incentivar la inversión privada, proveer de fuentes de financiamiento diversas y proporcionar certidumbre sobre los derechos de propiedad intelectual de manera que aumente la rentabilidad de la inversión en dichas industrias, contribuyendo a su desarrollo en el largo plazo. Además, debe buscar una sana competencia, que evite que las grandes corporaciones multinacionales tengan prácticas oligopólicas que generen asignaciones ineficientes de los ingresos y que reduzcan la diversidad de los bienes culturales.

La naturaleza multisectorial de las industrias creativas y culturales, requiere de políticas transversales, que generen estrategias que abarquen los diversos ámbitos de la economía creativa. En este sentido, China constituye un claro ejemplo de que cuando las políticas públicas se encuentran encaminadas a un mismo objetivo y se establecen medidas que involucran a los diferentes sectores del gobierno, se puede potencializar el impacto de este sector estratégico.

En México las industrias creativas contribuyen de manera considerable al PIB, sin embargo, gran parte se debe a las industrias interdependientes que no generan tanto valor agregado como las industrias clave o aquellas cuyo principal insumo es la creatividad. Se debe por un lado de fomentar la formación y profesionalización del sector que permita incrementar el capital humano capacitado por lo tanto la productividad laboral $y$, por otro lado, generar los mecanismos adecuados que permitan una adecuada remuneración de los 
empleos creativos y culturales, así como la asignación eficiente de recursos.

Por último, se debe de continuar trabajando en generar métodos adecuados que permitan medir el impacto económico de las industrias protegidas por el derecho de autor, pero sobretodo, en la recopilación de información con el fin de que dichas mediciones sean lo más exactas posibles y constituyan una herramienta adecuada para la elaboración de políticas públicas a largo plazo. En este sentido la publicación de la Cuenta satélite de cultura de México, elaborada por CONACULTA e INEGI en 2014, representa un gran avance. Sin embargo, la gran diferencia con otros estudios como el realizado por Piedras (2010), lleva a concluir que aún falta mucho para contar con información verídica sobre la importancia que tienen las industrias creativas, en particular, y la economía creativa, en general, en la economía del país.

ANEXO 1: TRATADOS Y CONVENIOS INTERNACIONALES FIRMADOS POR LOS PAÍSES SELECCIONADOS

\begin{tabular}{|c|c|c|c|c|c|c|c|c|c|c|c|c|}
\hline PAis & $\begin{array}{c}\text { CONVENIO DE } \\
\text { BERNA } \\
1886\end{array}$ & $\begin{array}{c}\text { CONVENCIÓN } \\
\text { DE ROMA } \\
1961\end{array}$ & $\begin{array}{c}\text { CONVENIO } \\
\text { PARA LA } \\
\text { PROTECCIÓN } \\
\text { DE } \\
\text { FONOGRAMAS } \\
1971\end{array}$ & $\begin{array}{c}\text { CONVENIO DE } \\
\text { BRUSELAS } \\
1974\end{array}$ & $\begin{array}{c}\text { TrATADO DE } \\
\text { LA OMPI } \\
\text { SOBRE } \\
\text { DERECHOS DE } \\
\text { AUTTR } \\
1996\end{array}$ & $\begin{array}{c}\text { TRATADO DE } \\
\text { LA OMPP } \\
\text { SOBRE } \\
\text { INTERPRETACIÓ } \\
\text { N O EJECUCIÓN } \\
\text { Y } \\
\text { FONOGRAMAS } \\
1996\end{array}$ & $\begin{array}{c}\text { ACUERDO } \\
\text { SOBRE LOS } \\
\text { ADPC } \\
1994\end{array}$ & $\begin{array}{c}\text { TRATADO DE } \\
\text { BEIING SOBRE } \\
\text { INTERPRETACIO } \\
\text { NES Y } \\
\text { EJECUCIONES } \\
\text { AUDIOVISUALE } \\
\text { S } \\
2012\end{array}$ & $\begin{array}{l}\text { TRATADO DE } \\
\text { MARRAKECH } \\
\text { PARA LAS } \\
\text { PERSONAS CON } \\
\text { DISCAPACIDAD } \\
\text { VISUAL } \\
2013\end{array}$ & $\begin{array}{c}\text { CONVENIO DE } \\
\text { LA OMPPI } \\
1967\end{array}$ & $\begin{array}{c}\text { CONVENCIÓN } \\
\text { UNIVERSAL } \\
\text { SOBRE } \\
\text { DERECHO DE } \\
\text { AUTOR } \\
\text { (UNESCO) } \\
1971\end{array}$ & $\begin{array}{l}\text { CONVENCIÓN } \\
\text { SOBRE LA } \\
\text { PROTECCIÓN DE } \\
\text { LA DIVERSIDAD } \\
\text { CULTURAL } \\
2005\end{array}$ \\
\hline \multirow{2}{*}{ Argentina } & $A$ & $\mathrm{~F}$ & A & $\mathrm{F}$ & $\mathrm{F}$ & $F$ & V & & $\mathrm{F}$ & $A$ & & $\mathrm{R}$ \\
\hline & 1967 & 1961 & 1973 & 1975 & 1997 & 1997 & 1995 & & 2014 & 1980 & & 2008 \\
\hline \multirow{2}{*}{ China } & A & & A & & A & A & V & F & F & A & A & R \\
\hline & 1992 & & 1993 & & 2007 & 2007 & 2001 & 2012 & 2013 & 1980 & 1973 & 2007 \\
\hline \multirow{2}{*}{ Filipinas } & A & A & $\mathrm{F}$ & & $\mathrm{F}$ & $\mathrm{F}$ & V & & & $F$ & & \\
\hline & 1950 & 1984 & 1972 & & 2002 & 2002 & 1995 & & & 1967 & & \\
\hline \multirow{2}{*}{ Hungria } & A & A & A & & R & R & V & F & & R & R & R \\
\hline & 1922 & 1994 & 1975 & & 1998 & 1998 & 1995 & 2012 & & 1969 & 1972 & 2008 \\
\hline \multirow{2}{*}{ México } & A & $\mathrm{F}$ & $F$ & F & F & F & V & F & F & $F$ & R & R \\
\hline & 1967 & 1961 & 1971 & 1974 & 1997 & 1997 & 1995 & 2012 & 2014 & 1967 & 1975 & 2006 \\
\hline \multirow{2}{*}{ Panamá } & A & A & F & A & F & F & V & & $F$ & $A$ & A & $R$ \\
\hline & 1996 & 1983 & 1972 & 1985 & 1997 & 1997 & 1997 & & 2013 & 1983 & 1980 & 2007 \\
\hline \multirow{2}{*}{ Perú } & A & A & A & A & A & A & V & F & $\mathrm{F}$ & $\mathrm{F}$ & A & A \\
\hline & 1988 & 1985 & 1985 & 1985 & 2001 & 2001 & 1995 & 2012 & 2013 & 1967 & 1985 & 2006 \\
\hline \multirow{2}{*}{ Rumania } & A & A & A & & R & R & V & F & & R & & A \\
\hline & 1926 & 1998 & 1998 & & 2001 & 2001 & 1995 & 2013 & & 1969 & & 2006 \\
\hline \multirow{2}{*}{ Tailandia } & A & & & & & & V & & & A & & \\
\hline & 1931 & & & & & & 1995 & & & 1989 & & \\
\hline \multirow{2}{*}{ Ucrania } & A & A & A & & A & A & V & & & $\mathrm{F}$ & & R \\
\hline & 1995 & 2002 & 1999 & & 2001 & 2001 & 2008 & & & 1967 & & 2010 \\
\hline
\end{tabular}

Nota: Las letras sobre los años se refieren a A=Adhesión, F=Firma, R=Ratificación, V=Vigencia

Fuente: WIPO Lex, OMPI 


\section{$\underline{\text { Referencias }}$}

- Buitrago, PF \& Duque, I.(2013). La Economía Naranja: Una oportunidad infinita, Washington, EUA: Banco Interamericano de Desarrollo. Recuperado de: http://publications.iadb.org/bitstream/handle/11319/3659/La\%20economia\%20naranja\%3a\%20Una\%20oportunidad\%20infinita.pdf?sequence=4. •Caballero, J.L. (2006). Principios Generales En Materia De Derecho De Autor Y Derechos Conexos. Limitaciones Y Excepciones. Marco Normativo Internacional. Acciones Para La Defensa De Los Derechos De Autor, Quinto Seminario Regional Sobre Propiedad Intelectual Para Jueces Y Fiscales De América Latina, Cartagena De Indias, Colombia: Ompi. Recuperado de Http://Www.Wipo.Int/Edocs/Mdocs/Lac/Es/ Ompi_Oepm_Oep_Pi_Ju_Ctg_06/Ompi_Oepm_Oep_Pi_Ju_Ctg_06_5.Pdf [Consultado El 23 De Octubre De 2014]. •Cornell University, INSEAD, \& WIPO (2014). The Global Innovation Index 2014: The Human Factor In innovation. Ginebra, Suiza: Cornell University, INSEAD, and WIPO. Recuperado de: https://www.globalinnovationindex.org/userfiles/file/reportpdf/GII-2014-v5.pdf • Gantchev, D. (2003). Guide on Surveying the Economic Contribution of the Copyright-Based Industries, Ginebra, Suiza: World Intellectual Property Organization. •Howkins, J. (2001). The Creative Economy: How People make Money from Ideas, Londres, Inglaterra: Penguin UK. •Maskus, K.(1997). The International Regulation of Intellectual Property, Preparado para la Conferencia de IESG Conference Regulation of International Trade and Investment. Nottingham, Inglaterra: Universidad de Nottingham. Recuperado de http://www.adelaide.edu.au /cies/papers/ sp9711.pdf. [Consultado el 23 de octubre de 2014]. •Maskus, K.(2000). The Economics of Intellectual Property Rights and Globalization: Dancing the Dual Distortion, en Intellectual Property Rights in the Global Economy, Washington, EUA: Institute for International Economics. •OMPI (2004). The Economic Contribution of Copyright-Based Industries in Hungary, Ginebra, Suiza: Organización Mundial de la Propiedad Intelectual (OMPI). Recuperado de: http://www.wipo.int/ export/sites/www/copyright/en/performance/pdf/econ_contribution_cr_hu.pdf • OMPI (2006). The Economic Contribution of Copyright-Based Industries in Mexico, Ginebra, Suiza: Organización Mundial de la Propiedad Intelectual (OMPI). Recuperado de: http://www.wipo.int/export/sites/www/copyright/en/performance/pdf/econ_contribution_cr_mx.pdf - OMPI (2008a). The Economic Contribution of Copyright-Based Industries in Ukraine, Ginebra, Suiza: Organización Mundial de la Propiedad Intelectual (OMPI). Recuperado de: http://www.wipo.int/export/sites/www/copyright/en/performance/pdf/econ_contribution_cr_ua.pdf •OMPI (2008b). The Economic Contribution of Copyright-Based Industries in the Philippines, Ginebra, Suiza: Organización Mundial de la Propiedad Intelectual (OMPI). Recuperado de: http://www. wipo.int/export/sites/www/copyright/en/performance/pdf/econ_contribution_cr_ph.pdf •OMPI (2009a). The Economic Contribution of Copyright-Based Industries in Panama, Ginebra, Suiza: Organización Mundial de la Propiedad Intelectual (OMPI). Recuperado de: http://www.wipo.int/export/sites/www/copyright/en/performance/pdf/econ_contribution_ cr_pa.pdf - OMPI (2009b). The Economic Contribution of Copyright-Based Industries in Peru. Ginebra, Suiza: Organización Mundial de la Propiedad Intelectual (OMPI), Recuperado de: http://www.wipo.int/export/sites/www/copyright/en/ performance/pdf/econ_contribution_cr_pe.pdf •OMPI (2009c). The Economic Contribution of Copyright-Based Industries in China. Ginebra, Suiza: Organización Mundial de la Propiedad Intelectual (OMPI), Recuperado de: http://www. wipo.int/export/sites/www/copyright/en/performance/pdf/econ_contribution_cr_cn.pdf •OMPI (2010a). Segundo documento analítico sobre las limitaciones y excepciones en vigor, Ginebra, Suiza: World Intellectual Property Organization. Recuperado de: http://www.wipo.int/edocs/mdocs/copyright/es/sccr_20/sccr_20_4.pdf. [Consultado el 23 de octubre de 2014]. - OMPI (2010b). The Economic Contribution of Copyright-Based Industries in Romania, Ginebra, Suiza: Organización Mundial de la Propiedad Intelectual (OMPI). Recuperado de: http://www.wipo.int/export/sites/www/copyright/en/ performance/pdf/econ_contribution_cr_ro.pdf •OMPI (2012). The Economic Contribution of Copyright-Based Industries in Thailand, Ginebra, Suiza: Organización Mundial de la Propiedad Intelectual (OMPI). Recuperado de: http://www. wipo.int/export/sites/www/copyright/en/performance/pdf/econ_contribution_cr_th.pdf • OMPI (2013). The Economic Contribution of Copyright-Based Industries in Argentina, Ginebra, Suiza: Organización Mundial de la Propiedad Intelectual (OMPI). Recuperado de: http://www.wipo.int/export/sites/www/copyright/en/performance/pdf/econ_contribution_ cr_ar.pdf •OMPI (2014). WIPO Studies on the Economic Contribution of the Copyright Industries, Ginebra, Suiza: Organización Mundial de la Propiedad Intelectual (OMPI). Recuperado de: http://www.wipo.int/export/sites/www/copyright/ en/performance/pdf/economic_contribution_analysis_2012.pdf • Oxford Economics (2013). The Economic Impact of the Creative Industries in the Americas, Washington, EUA: Organización de los Estados Americanos (OEA), el Banco Interamericano de Desarrollo (BID) y el British Council. Recuperado de: http://www.oas.org/documents/eng/press/BC_America_report_SB_v6_eng.pdf •Piedras, E. (2010) Industrias Culturales para el Desarrollo Integral en México y América Latina, DF, México: The Competitive Intelligence Unit. Recuperado de: http://www.iadb.org/OM/pdf/EPiedrasP1.pdf -Quartesan, A; Romis, M. \& Lanzafame, F. (2007). Las Industrias Culturales en América Latina y el Caribe: Desafíos y Oportunidades, Washington, EUA: Banco Interamericano de Desarrollo (BID). Recuperado de: http://idbdocs.iadb.org/ wsdocs/getdocument.aspx?docnum=1156415 •Sistema Económico Latinoamericano y del Caribe (SELA) (2011). Incentivo a las Industrias Culturales y Creativas en América Latina y el Caribe. Caracas, Venezuela: SELA. Recuperado de: http:// 
www.sela.org/attach/258/EDOCS/SRed/ 2011/06/T023600004770-0-Incentivo_a_las_Industrias_Creativas_y_Culturales-_ Di_08-11.pdf. [Consultado el 23 de octubre de 2014]. - Towse, R. (2006a). Copyright and Creativity: Cultural Economics for the 21st Century, Review of Economic Research on Copyright Issues, 3(2); 83-91. •Towse, R. (ed.). (2011). A handbook of cultural economics. Cheltenham, Inglaterra y Northampton, EUA: Edward Elgar Publishing. •Towse, R. Handke, C y Stepan, P. (2008). The Economics of Copyright Law: A Stocktake of the Literature, Review of Economic Research on Copyright Issues, vol. 5(1), 1-22 •UNESCO. (2013). Creative Economy Report 2013, Special Edition: Widening Local Development Pathaways, Nueva York, EUA y París, Francia: UNDP/UNESCO. Recuperado de: www.unesco.org/culture/pdf/creative-economy-report-2013.pdf [Consultado el 23 de octubre de 2014]. • United Nations (UN) (2008). Creative Economy Report 2008. The Challenge of Assessing the Creative Economy: Towards Informed Policy Making, Ginebra, Suiza y Nueva York, EUA: United Nations Conference on Trade and Development (UNCTAD)- United Nations Development Programme (UNDP). Recuperado de: http://unctad.org/es/Docs/ditc20082cer_en.pdf. [Consultado el 23 de octubre de 2014]. - United Nations (UN) (2010). Creative Economy Report 2010. Creative Economy: A Feasible Development Option, Ginebra, Suiza y Nueva York, EUA: United Nations Conference on Trade and Development (UNCTAD)- United Nations Development Programme (UNDP). Recuperado de: http://unctad.org/es/Docs/ditctab20103_en.pdf. [Consultado el 23 de octubre de 2014]. • Van der Pol, H (2007). Key Role of Cultural and Creative Industries in the Economy, OECD Second World Forum, United Nations Educational, Scientific and Cultural Organization. Recuperado de: http://www.oecd.org/site/ worldforum06 /38703999.pdf •World Economic Forum (WEF) (2014). The Global Competitiveness Report 2014 - 2015, Ginebra, Suiza: World Economic Forum. Recuperado de: http://www3.weforum.org/docs/WEF_GlobalCompetitivenessReport_2014-15.pdf •Institutos de Derechos de Autor y Propiedad Intelectual consultados

Argentina Dirección Nacional del Derecho de Autor de Argentina (http://www.jus.gob.ar/derecho-de-autor.aspx) Instituto Nacional de la Propiedad Industrial (INPI) de Argentina (http://www.inpi.gov.ar) China National Copyright Administration of China (NCAC) (http://www.ncac.gov.cn) Patent Office / State Intellectual Property Office of the P.R.C (SIPO) (http://www.sipo.gov.cn) Trademark Office / State Administration for Industry and Commerce of the People's Republic of China (SAIC) (http://sbj.saic.gov.cn) Filipinas Intellectual Property Office of Philippines (IPOPHIL) •(http://www.ipophil. gov.ph/index.php) Hungría Hungarian Intellectual Property Office (HIPO) • Copyright Department (http://www.hipo.gov. hu) México Instituto Nacional del Derecho de Autor (INDAUTOR) (http://www.indautor.gob.mx ) •Instituto Mexicano de la Propiedad Industrial (IMPI) (http://www.impi.gob.mx/) Panamá Dirección Nacional de Derecho de Autor •Ministerio de Comercio e Industrias de Panamá -Dirección General del Registro de la Propiedad Industrial (DIGERPI) •Ministerio de Comercio e Industrias (DIGERPI) (http://www.digerpi.gob.pa/) Perú Presidencia del Consejo de Ministros (PCM) •Instituto Nacional de Defensa de la Competencia y de la Protección de la Propiedad Intelectual (INDECOPI) (http://www.indecopi. gob.pe) Rumania Romanian Copyright Office (ORDA) (http://www.orda.ro/) • State Office for Inventions and Trademarks (http://www.osim.ro) Tailandia Department of Intellectual Property (DIP) •Ministry of Commerce (http://www.ipthailand.go.th/en/) Ucrania State Intellectual Property Service of Ukraine (SIPS) •(http://www.sips.gov.ua/en/index.html)

Leyes consultadas Argentina Ley N 11.723 sobre el Régimen Legal de la Propiedad Intelectual http://www.wipo.int/edocs/ lexdocs/laws/es/ar/ar077es.pdf China Copyright Law of the People's Republic of China •http://www.wipo.int/edocs/lexdocs/ laws/en/cn/cn031en.pdf Filipinas Intellectual Property Code of the Philippines (Republic Act No. 8293)•http://www.wipo. int/edocs/lexdocs/laws/en/ph/ph001en.pdf Hungría Act No. LXXVI of 1999 on Copyright (consolidated text as of January 1, 2007) •http://www.wipo.int/edocs/lexdocs/laws/en/hu/hu084en.pdf México Ley Federal del Derecho de Autor (refundida hasta el 14 de julio de 2014) •http://www.wipo.int/edocs/lexdocs/laws/es/mx/mx140es.pdf Panamá Ley N 64 de 10 de Octubre de 2012 sobre el Derecho de Autor y Derechos Conexos •http://www.wipo.int/edocs/lexdocs/laws/es/pa/pa043es.pdf Perú Decreto 822 Ley sobre Derechos de Autor •http://www.wipo.int/edocs/lexdocs/laws/es/pa/pa043es.pdf Rumania Law No. 8 of March 14, 1996 on Copyright and Neighboring Rights •http://www.wipo.int/edocs/lexdocs/laws/en/ro/ro025en.pdf Tailandia Copyright Act of B.E. 2537 (1994) • http://www.wipo.int/edocs/lexdocs/laws/en/th/th001en.pdf •Ucrania Law on Copyright and Related Rights •http://www.wipo.int/edocs/lexdocs/laws/en/ua/ua005en.pdf 